\title{
SCIENTIFIC REP RTS \\ Author Correction: Transitions from Ideal to Intermediate Cholesterol Levels may vary by Cholesterol Metric
}

\author{
Joseph C. Engeda $\mathbb{1}^{1}$, Katelyn M. Holliday ${ }^{1}$, Shakia T. Hardy ${ }^{1}$, Sujatro Chakladar ${ }^{2}$, Dan-Yu Lin ${ }^{2}$, \\ Gregory A. Talavera ${ }^{4}$, Barbara V. Howard ${ }^{5}$, Martha L. Daviglus ${ }^{6}$, Amber Pirzada ${ }^{6}$, Pamela J. \\ Schreiner ${ }^{7}$, Donglin Zeng ${ }^{2} \&$ Christy L. Avery ${ }^{1,3}$
}

Correction to: Scientific Reports https://doi.org/10.1038/s41598-018-20660-2, published online 09 February 2018

The Acknowledgements section in this Article is incomplete.

"The Coronary Artery Risk Development in Young Adults Study (CARDIA) is conducted and supported by the National Heart, Lung, and Blood Institute (NHLBI) in collaboration with the University of Alabama at Birmingham (HHSN268201300025C \& HHSN268201300026C), Northwestern University (HHSN268201300027C), University of Minnesota (HHSN268201300028C), Kaiser Foundation Research Institute (HHSN268201300029C), and Johns Hopkins University School of Medicine (HHSN268200900041C). CARDIA is also partially supported by the Intramural Research Program of the National Institute on Aging (NIA) and an intra-agency agreement between NIA and NHLBI (AG0005). This manuscript has been reviewed by CARDIA for scientific content. This work was supported by National Heart, Lung, and Blood Institute training grant T32 predoctoral fellow T32HL007055."

should read:

"The authors thank the staff and participants of HCHS/SOL (Investigators website - http://www.cscc.unc. edu.libproxy.lib.unc.edu/hchs/), NHANES, and the Coronary Artery Risk Development in Young Adults Study (CARDIA) for their important contributions. CARDIA is conducted and supported by the National Heart, Lung, and Blood Institute (NHLBI) in collaboration with the University of Alabama at Birmingham (HHSN268201300025C \& HHSN268201300026C), Northwestern University (HHSN268201300027C), University of Minnesota (HHSN268201300028C), Kaiser Foundation Research Institute (HHSN268201300029C), and Johns Hopkins University School of Medicine (HHSN268200900041C). CARDIA is also partially supported by the Intramural Research Program of the National Institute on Aging (NIA) and an intra-agency agreement between NIA and NHLBI (AG0005). This manuscript has been reviewed by CARDIA for scientific content. This work was supported by National Heart, Lung, and Blood Institute training grant T32 predoctoral fellow T32HL007055."

${ }^{1}$ Departments of Epidemiology, the University of North Carolina at Chapel Hill, Chapel Hill, NC, USA. ${ }^{2}$ Departments of Biostatistics, the University of North Carolina at Chapel Hill, Chapel Hill, NC, USA. ${ }^{3}$ Carolina Population Center, the University of North Carolina at Chapel Hill, Chapel Hill, NC, USA. ${ }^{4}$ Division of Health Promotion and Behavioral Science, San Diego State University, San Diego, CA, USA. ${ }^{5}$ MedStar Health Research Institute and Georgetown/ Howard Universities Center for Clinical and Translational Sciences, Hyattsville, MD, USA. ${ }^{6}$ Institute for Minority Health Research, University of Illinois at Chicago, Chicago, IL, USA. ${ }^{7}$ Division of Epidemiology and Community Health, University of Minnesota, Minneapolis, MN, USA. Correspondence and requests for materials should be addressed to J.C.E. (email: Engeda@email.unc.edu) 
(i) Open Access This article is licensed under a Creative Commons Attribution 4.0 International License, which permits use, sharing, adaptation, distribution and reproduction in any medium or format, as long as you give appropriate credit to the original author(s) and the source, provide a link to the Creative Commons license, and indicate if changes were made. The images or other third party material in this article are included in the article's Creative Commons license, unless indicated otherwise in a credit line to the material. If material is not included in the article's Creative Commons license and your intended use is not permitted by statutory regulation or exceeds the permitted use, you will need to obtain permission directly from the copyright holder. To view a copy of this license, visit http://creativecommons.org/licenses/by/4.0/.

(C) The Author(s) 2018 